\title{
Forest environmental frontiers around the globe: Old patterns and new trends in forest governance
}

\author{
Georg Winkel, Metodi Sotirov, Cassandra Moseley
}

Published online: 18 October 2021

\begin{abstract}
Forests are subject to a huge variety of often competing socio-economic demands and environmental change. This paper assesses the related conflicts that occur along what we label to be a "Global Forest Environmental Frontier". Assessing 11 contributions to a special issue on the same topic, it summarizes the main contents of these papers and concludes with an assessment of major trends. The contributions to the special issue take both a regional and topic-related approach, assessing forest environmental conflicts on all five forested continents and investigating issues such as forest biodiversity conservation, climate change adaptation and mitigation, environmental justice and equity, development, and forest management and conservation discourses. Taken together, they provide an overview on the multiple facets of the Global Forest Environmental Frontier, but also identify some shared patterns and trajectories, which are outlined at the end of this paper.
\end{abstract}

Keywords Conservation - Environmental governance · Forest policy $\cdot$ Forest use $\cdot$ Natural resource policy

\section{INTRODUCTION}

In the last 50 years, forest governance across the world has been characterized by a major divide between environmental conservation concerns on the one hand, and economic forestry and agricultural production demands on the other, with diverse societal needs (e.g., related to livelihoods, employment, recreation, spiritual and cultural demands) cutting across multiple sides. This "Global Forest Environmental Frontier", as we refer to this phenomenon here, has diverse regional facets. For example, it includes conflicts between amenity-oriented environmental/social groups and commodity-oriented forest sector actors in Canada (Saarikoski et al. 2013), the US (Winkel 2014), Australia (Lane 2003), Scandinavia (Sandström et al. 2013; Lindahl et al. 2017), and Russia (Dobrynin et al. 2020), conflicts related to deforestation, illegal logging and livelihoods-and related policies to tackle these issues-in the Amazon (Hecht 2012), Central Africa (Butsic et al. 2015) and South-East Asia (Yasmi et al. 2009), and "multipleuse" forestry controversies in Central and Eastern Europe (Sotirov and Winkel 2016; Borrass et al. 2017).

Although these conflicts are different depending on the region and particular issue at stake, they also show important similarities, including potentially actors, networks, institutions, and sectoral ideologies and interests. At the same time, the Global Forest Environmental Frontier has been constantly evolving as societies, economies, and environmental conditions change.

Despite numerous forest environmental conflicts across the globe, and numerous related publications, to the best of our knowledge, there has not yet been an attempt to explore the Global Forest Environmental Frontier in a systematic and comprehensive way, i.e., with the aim to tackle prominent controversies in distinct world regions and identify similar patterns across topics and regions. However, such an undertaking is relevant and timely for two main reasons. First, forests are receiving renewed attention for their importance for climate change mitigation and biodiversity conservation, along with recreational and cultural use for increasingly urbanized societies. Second, forest environmental conflicts have become increasingly urgent in certain cases, e.g., in the wake of calamities connected to climate change, in relation to progressing deforestation in several tropical regions, intensified forest management in other countries in response to industrial 
demands, and/or climate change mitigation connected to support for bioenergy use.

In this special issue, we present socio-environmental research that has been conducted along the Global Forest Environmental Frontier in major forested regions of the world. This collection of papers focuses on policy analysis, environmental governance, sociology, and political economy with the aim to assess the current state and possible future trajectories of forest environmental conflicts around the globe. More specifically, we ask the following research questions:

- What characterizes the Global Forest Environmental Frontier in relation to different issues and regions?

- How have the frontiers developed over time? Have the conflicts increased or decreased? Have the topics of the debates and the solutions to address them changed or remained stable?

The special issue brings together different regional insights and analytical perspectives and includes both review/"history tracing" articles and original research contributions relating to major topics along the frontier. We take a regional and topicwise approach. The paper contributions tackle policy issues and governance arrangements of high relevance for the global forest frontier (e.g., illegal logging, biodiversity, climate change mitigation and adaptation, the agriculture-forest-water nexus, and restoration) and cover most of the major forested regions of the world (Central Africa, North and South America, Europe, North and East Asia, Australia and New Zealand). This allows for identification and categorization of frontier conflicts, as well as application of multiple intra- and inter-disciplinary theoretical perspectives for analyzing developments and extracting lessons.

The special issue provides a topical and up-to-date analysis on forest environmental controversies across the globe. For policy makers, the special issue not only offers new insights into the diversity and complexity of specific topics, but also identifies common patterns at the Global Forest Environmental Frontier, including inspiration regarding conflict resolutions. For scientists, the special issue contributes novel insights and a compilation of the existing knowledge not only of specific topics, but also across topics, building upon the questions raised above on a global scale.

In the following section, we summarize the individual contributions to the special issue and then draw common themes across the contributions to address the research questions outlined above.

\section{PAPER CONTRIBUTIONS}

The papers in this special issue begin with the largest (forest) country on the planet, the Russian Federation.
Despite Russia covering around one fifth of the world's forests, the literature on Russian forest environmental conflicts is sparse. Dobrynin et al. (2021) approach this gap by examining the discourses that non-state and state actors use to conceptualize forests and actors' belief that forests should be managed to address both economic interests and conservation values, including climate change. This is opposed to the widespread practices of 'wood mining' in Russia (i.e., the clear-cut harvesting often seen with primary forests). The authors find that the discourses change over time and argue that there are two major discursive threads in recent years-one focused on the intensive management of secondary forests through even-aged management and the other focused on protection of primary forests. These two discourses have been integrated into forestry debates as well as forestry institutions. The discourses interact with each other, as shifting coalitions of non-state actors and industry and state actors seek to collaborate and build winning alliances to change forest management via both public policies and non-state marketdriven forest certification rules. What is particularly interesting in the analysis of Russian forest policy discourses is the point that intensive forestry, largely following a Scandinavian model, is advocated for also by environmental interest groups as a means to reduce harvesting pressure on remaining primary forests, in combination with a strong traditional focus on protecting intact forest landscapes. This is in contrast to the European Union (EU) forest environmental policy debate where the same Scandinavian model of intensive forestry with a focus on largescale clearcutting, artificial regeneration, and even-aged shorter rotation timber harvesting is under increasing critique from nature conservation authorities, environmental NGOs, indigenous groups, and scientists (Sandström et al. 2013; Lindahl et al. 2017; Sotirov and Storch 2018).

This EU forest policy debate, and the evolution of EU forest environmental policy over time, is the topic of the next paper by Sotirov et al. (2021). The authors trace the evolution of the forest environmental frontier in the pluralistic multi-level governance system of the EU. They mainly focus on the analysis of European environmental forest policy making shaped by progressing European integration. They note ideological divisions and diverging interests between and within public and private actors, EU institutions, and Member States. The paper shows how different actor coalitions composed of state and non-state actors try to influence EU policy making, resulting in periods of policy change and stability in regard to key issue areas such as forest biodiversity conservation (Natura 2000), timber legality assurance vs. forest sustainability certification along global supply chains, and climate protection in the land use, land use change and forestry sector (LULUCF). First, the authors show that the EU's 
environmental forest policy development is characterized by a stable, long-term line-up of rivaling policy advocacy coalitions that are characterized by fundamentally different policy core beliefs, interests and related institutional preferences of an environmental and forest use coalition. Second, they detect dynamic processes of strategic alliances forming across coalitions in relation to narrow policy issues, and find that such strategic cross-coalitional alliances and shifting coalitions are often instrumental to enable EU environmental forest policy change. Finally, they show that change in EU environmental forest policy often entails a mixture of core beliefs from different coalitions, as an outcome of strategic alliance building and related policy compromises. In summary, with the help of (temporal) strategic alliances between environmental and select economic actors (e.g., non-bioeconomy industries, timber traders and retailers, agricultural industries), and despite the opposition of the forestry coalition, the environmental coalition was able to establish EU environmental forest policies in the three investigated issue areas (Natura 2000, FLEGT, and LULUCF). However, the authors suggest that there is a need to further explore how such a gradual success of the environmental coalition at the EU policy level might be counterbalanced by reluctant implementation at the Member State level, and in forest management practices. Here, economic forestry interests may prevail, especially in some of the forest rich EU Member States with economically important forest industry sectors.

Crossing the Atlantic Ocean, Schultz et al. (2021) focus on the western United States and begin their paper with the observation that this region has moved into an era of mega disturbances. These forests have long been disturbance driven, but wildfires and insect outbreaks are growing far larger and increasingly shape not only the forests, but also how the forests are governed. The authors see a movement away from the early twentieth century professionalized and autonomous U.S. Forest Service toward a complex networked governance system that has responded to national level stalemate and capacity loss with institutional innovation at multiple scales. The authors posit that responses to disturbance are shaped by institutional history, evolving discourses, and institutional innovations. Understanding these dynamics requires consideration of micro-, meso-, and macro-governance scales. Congressional legislation has been infrequent and focused on authorizing new programs with limited impacts on practice. Instead, there has been an "informal expansion of multi-actor governance networks, devolution of authority to states, NGOs, and communities, and new policy tools to support resourcesharing and capacity-building across ownerships." At local and regional scales, there has been considerable institutional experimentation, especially in the building of partnerships, collaboration, and governance networks that bring together state and non-state actors into de facto governing coalitions. These interconnected systems are dynamic and continually subject to forces that at once promote status and advance change.

Subsequently, the paper by Kanowski and Edwards (2021) investigates five contemporary forest frontiers for both New Zealand and Australia, two countries that share many historical and contemporary commonalities but show also significant differences. First, there is a forest agricultural frontier, as in many parts of the world, mostly characterized by a history of deforestation for the purpose of expanding agricultural land use, but also connected to current debates about achieving more sustainable land use practices in both countries. Second, there is a "First Nations" frontier determined by both countries' colonial history characterized by (i) the "transfer" of most of the forest land and land use rights from First Nations to the European settlers; (ii) a related contemporary period characterized by disputes over the restitution of property and use rights to both Aboriginals and Māori; and (iii) a (partially) successful restitution of forest property, at least in the case of New Zealand. This frontier encompasses and closely relates to disputes about appropriate land use practices, which are connected to a third forest frontier, labeled as the "Forest Management" frontier. This frontier is characterized by a polarization between conservation and forest use/industry interests. In New Zealand, this frontier has been partially pacified with policy decisions in the 1990s to protect remaining native forest lands, and a de facto split of forest lands into strictly protected native forests and intensively managed plantations with non-native tree species (where conflicts about intense management continues). However, in Australia, conflicts related to harvesting of such forest lands continue. Here, forest fires and questions about forest management to mitigate fire risks add to the debate, involving conflicting views on the necessity of different forest management measures. Fourth, the authors identify an "Urban and Peri-urban" forest frontier, characterized by rapidly growing urban and periurban areas in both countries, and an often close interlinkage between forests and settlements. On the one hand, this results in forest losses and conflicts between forest conservation and urban development; on the other hand, various "urban" demands toward forests and their management (e.g., for leisure, public health) increase in importance, and (new) conflicts relating to increasing fire danger occur. The latter risk is spurred especially in Australia by the fifth and final frontier, the "Forest-Climate" frontier. This frontier is characterized by increasing impacts of a warmer climate (e.g., decreases in the productivity of plantation forests and increases of the risks of fire in Australia, and possible increases in the profitability 
of plantations in New Zealand). This frontier is also impacted by the potentially large importance of forests under climate mitigation considerations. Altogether, these five frontiers impact forest policy and management in both countries, with some variations, and display close interconnections between them.

A classical forest frontier of global importance is the focus of the next paper by Pokorny et al. (2021), which focuses on the ongoing forest transition in the Brazilian Amazon. The authors take a long-term historical perspective, starting in the 1960s. They distinguish eight sociopolitical phases of Brazilian policy and socio-economic development, ranging from an "Awakening Interest" phase in the 1960s and 1970s connected to the military governments which at the time targeted socio-economic development of the Amazon region, up to "Populist Neoliberalism" under the current Bolsonaro government. The authors investigate the socio-economic and environmental policies of the respective governments and their impact on forests, society and the economy of the Amazon region. For the latter, they investigate a set of social, economic, and environmental indicators, including deforestation rates, to trace the impacts of changing policies on the Amazon Forest and socio-economic development. While social and environmental concerns have increasingly entered the political debate since the 1990s, resulting in novel policies to conserve forests and improve livelihoods in the Amazon region, the main argument of Pokorny et al. (2021) is that the long-standing patterns of deforestation caused mainly by agricultural expansion and only modest social equality gains continue. This led the authors to call for "a coherent, long-term commitment and change in the collective mindset", which would be needed to bring the Amazon forest frontier back "in control".

Opposite to the deforestation frontier in the Amazon, De Jong et al. (2021) use a similar historical perspective to investigate what they label the "Forest Restoration Frontier", referring to the development of forest restoration around the globe. To date, forest restoration has resulted in approximately 300 million ha of restored forests, and in the recent decade has become a major global forest policy concern, exemplified by various global (e.g., the Bonn Challenge) or regional (e.g., the EU Green Deal's target to plant 3 billion trees) initiatives. De Jong et al. (2021) distinguish different historical phases of restoration policies and practices, and show that those policies can largely be connected to three major objectives: (1) to produce forest products or spaces for recreation; (2) to produce regulating ecosystem services (sequestered carbon, erosion control); and (3) to improve rural livelihoods. Priorities among these objectives have changed over time. In the recent decade, biodiversity concerns have complimented the restoration goals. The authors assess the changing policies and underlying drivers, as well as elaborate on possible impacts. They conclude with expressing some reservation over whether contemporary major forest restoration targets will reach their ambitions in terms of both forest area but also restoration impacts.

The tropics remain at the center in the next two papers of the special issue. Brockhaus et al. (2021) investigate the potential of forest-related climate policy to incentivize "transformational" change in the Global South, i.e. governance change to overcome deeply rooted patterns of inequality embedded in forest frontiers. Drawing on a political economy lens, they analyze four cases covering several countries in the Global South to investigate to what extent policy approaches such as reducing emissions from deforestation and forest degradation (REDD) have been able to bring about transformational change. They find, however, that such change has largely not happened. Furthermore, new climate related policies rather tend to reinforce ideas of large-scale "technical fixes", and partially mirror (post-) colonial patterns and discourses that perpetuate inequalities. This is the case, for instance, in relation to the prominent idea that pastoralists and smallholders need to modernize the way they practice agriculture and move away from grazing and shifting cultivation. Even more, in one case, climate related policy ideas seem primarily designed for the purpose of accessing international climate money. Yet, Brockhaus et al. (2021) also observe changes related to improved transparency along value chains that make it easier to connect certain practices to deforestation and unsustainable management. The authors conclude by arguing that equitable outcomes would "require a strong discursive shift within dominant institutions and among policy actors to redress policies that place responsibilities and burdens on local people in the Global South, while benefits from deforestation and maladaptation are taken elsewhere." They demand a "shared transformational objective and priority to keep forests standing" across all case studies and regions.

Ramcilovic-Suominen et al. (2021) focus on understanding how international efforts to address climate change by reducing deforestation and forest degradation and enhance forest carbon and biodiversity conservation (via REDD+) intersect with authoritarian state governance at the physical forest frontier to impact forest dwelling peoples. Specifically, this empirical paper sheds light on how REDD+ plays out on the ground in particular ethnic minority communities in Laos. The authors posit that, although REDD+ is designed with several social and environmental safeguards, the primacy it places on state sovereignty and the role of state actors in decision-making and resource allocation creates substantial environmental justice challenges, especially in authoritarian contexts. Although payments under REDD+ are based on 
performance, national governments are the ultimate decision-makers about whether and how to participate in REDD + . This paper examines three dimensions of environmental justice-procedural justice, distributional justice, and recognitional justice-which allows the authors to unpack the diverse challenges in REDD+ implementation. For example, environmental justice problems include performative decision-making processes, exclusion of villagers from carbon-related revenue opportunities, and political exclusion of key groups such as women and nondominant language speakers. In some ways, these case studies reveal REDD+ as an international aid mechanism that reinforces, rather than changes, existing dynamics between the international aid community, the state, and forest-dependent communities.

In the next paper, Takahashi et al. (2021) deal with the implications of forest ecosystem disservices for national forest policies and the public administration of forests in Japan. Defining ecosystem disservices as harmful effects to human wellbeing, the authors first show that the big share of planted forests established in Japan in recent decades has caused a range of forest ecosystem disservices in the country such as wildlife nuisance and damage, pollen allergies, and damaging impacts of driftwood. The authors provide evidence that these forest ecosystem disservices do not constitute dramatic events that would cause radical changes in the slow, incremental policy processes that have characterized forest policies design and implementation since the beginning of the modern Japanese state. Forest policy responses have been rather characterized by incrementalism, central mobilization, and hegemony of career civil servants. In particular, to address wildlife and forestry/agriculture issues, policy responses and measures have focused more on technical solutions such as building fences or controlling populations, compared to naturebased solutions such as developing forest ecosystems that are compatible with wildlife and other land uses. Even though the policies on wildlife management under the jurisdiction of the Japanese Ministry of the Environment have changed significantly (e.g., when novel science-based approaches were adopted), policies related to wildlife management undertaken by the Forestry Agency have not changed drastically (e.g., in the case of the continuation of protective measures for plantation forests against wildlife). By looking at three cases of ecosystem disservices, the authors conclude that the slow and marginal changes in regulating these disservices can be explained by the incrementalism and path dependency in forest policy in Japan.

The last two contributions of the special issue address biodiversity conservation and the forestry-water-agriculture nexus. In the first paper, Angelstam et al. (2021) show how the economic exploitation of natural forests leads to negative net effects on biodiversity by reducing naturalness and intact forest landscapes in both boreal and continental forests in the Global North and in tropical forests in the Global South. The authors find that the connectivity among remnant forests with higher levels of naturalness is poor, and show that "forest transitions" increase the area of planted forests with low levels of naturalness in the forest landscape matrix. The authors then identify a range of global and national forest conservation policies and instruments that support protected forest areas in view of maintaining functional forest habitat networks. By focusing on exploring the situation in 16 case study areas located in boreal, temperate and tropical forest regions on five continents, the authors map protected area instruments, assess their effectiveness, analyze policy implementation tools, and investigate the effects on protected areas originating from their surroundings. They conclude that the trajectories for forest biodiversity conservation were generally negative. This is first explained by the result that strict conservation instruments are on average used for lower proportions of areas with current native forest cover. Secondly, the authors find that the effectiveness of habitat networks depended on a range of ecological and policy drivers such as representativeness, habitat quality and functional connectivity, and is constrained through a variety of factors including resource extraction in protected areas, the long-time horizons of landscape restoration, and the existence of "paper parks" with little impact on management practices on the ground. Thirdly, the authors find that regulatory policy instruments dominated over economic and informational ones, but their effectiveness is low. Fourthly, this is explained by the domination of a range of negative matrix effects (improved road access, use and conservation clashes, untrustworthy or lacking forest data, old forest decline causing loss of naturalness, impacts of exotic invasive organisms, and externalities stemming from other land uses such as mining or wind power) over positive ones (protective forests, buffer zones, inaccessibility) in most case studies. The authors conclude that the net effects of forestry intensification, matrix effects and expansion of frontiers of transformation of natural and near-natural forest remnants and the environmental frontier's encouragement of sufficient amounts of protected areas and functional habitat network on the ground were generally negative.

In the final contribution to this special issue, Seijger et al. (2021) broaden water-forest research by proposing an expanded, inter-disciplinary research approach that combines conceptual, analytical, and empirical aspects that until now have remained largely unaddressed. Conceptually, the approach adopts a 'frontier' perspective to comprehend the exploration, exploitation and contestations over forest and water resources in agriculture-forest 
landscapes, going beyond the focus of biophysical studies on land use change and pairwise comparisons. Analytically, the approach looks at both agriculture as the single biggest driver of deforestation and the linkage of forest and agricultural policies with water policies regulating water resource management. This contrasts with biophysical studies which tend to treat agriculture and policies as boundary phenomena for forest-water systems. Empirically, their approach suggests a focus on deforestation and reforestation hotspots in both the Global North and the Global South, unlike other water-forest studies that focus only on deforestation in the Global South. They illuminate the dynamic interplay of water and policies in oscillating agriculture-forest frontiers, with changing outcomes for people and the environment. In doing this, the authors broaden the water-forest research field to include an agriculture-forest frontier conceptualization that links sectoral policies to water resources in a spatial-temporal context. The approach can be used to test a working hypothesis that reversing land cover changes along the frontier is constrained due to substantial changes in hydrology, which is then helpful to study hydrological regime shifts in the Anthropocene and the contribution of human alterations. Another hypothesis is that in the agriculture-forest frontier there is little policy coherence across policy levels for the policy sectors of water, forest and agriculture. Last, but not least, the authors hypothesize that when studying agriculture-forest frontiers over time, a back-and-forth move can be observed in water resources, land use and policies.

\section{CONCLUSIONS}

What can be concluded from the 11 individual contributions in this special issue regarding Global Forest Environmental frontier? To begin with, we identify four major frontiers that are present to different degrees in various regions around the planet and are frequently also interconnected:

First, the traditional forest frontier characterized by deforestation, forest degradation, and land use change related to agricultural expansion (but also to urban development, as for instance discussed in Kanowski and Edwards (2021)) is still important and dominates forest environmental policy conflicts especially in the tropics (Pokorny et al. 2021; Brockhaus et al. 2021; RamcilovicSuominen et al. 2021). This frontier is connected to a reverse land use change frontier- the restoration frontierthat is increasingly global by nature (DeJong et al. 2021; Schultz et al. 2021; Sotirov et al. 2021).

Second, another key forest environmental frontier of global nature is characterized by the clashing world views and policy paradigms of nature/biodiversity conservation and forest use actors (Dobrynin et al. 2021; Kanowski and Edwards 2021; Pokorny et al. 2021; Sotirov et al. 2021; Schultz et al 2021). Specifically, controversies between environmental/conservation and forest use (and in some regions broader land use) policy actors are characterizing the forest environmental frontier in many, if not all, world regions and are the dominant conflict pattern in several of them.

Third, conflicts related to the distribution of forest use rights between different groups of the population, for instance between different ethnicities (e.g., First Nations and today's majority populations), characterize the forest environmental frontier in several world regions, especially in the tropical world regions (Pokorny et al. 2021; Ramcilovic-Suominen et al. 2021) and Australia/New Zealand (Kanowski and Edwards 2021). Related to that, controversies over the best way to govern diverging demands and expectations of forests occur, marking, for instance, a frontier between formal and informal practices and ways to account for them, but also between (free) market governance and state intervention.

Fourth, climate change (adaptation and mitigation) and its increasing impact on forests across the planet results in an increasingly significant forest frontier that is characterized by the physical impact of a warmer climate (mostly by means of larger, more intense and more frequent disturbances), as well as by the often deeply ideologically rooted conflicts of how to deal with such shifting environmental patterns (Brockhaus et al. 2021; Ramcilovic-Suominen et al. 2021; Seijger et al. 2021; Schulz et al. 2021; Sotirov et al. 2021; Takahashi et al. 2021).

These forest environmental frontiers have evolved over time and space, and specific types of conflicts seem to occur more prominently at different stages of the forest transition process. More specifically, the forest transition theory (Mather 1992) investigates the transition of the world's forests in different countries over time, postulating initially an undisturbed forest phase characterized by rather low population densities and a forest-dependent society, followed by a deforestation phase that is usually characterized by constant forest loss due to agricultural development, and forest restoration phases characterized by net gains in forest cover due to plantations, forest restoration, and/or natural forest regrowth, usually connected to progressing socio-economic development. The deforestation phase is arguably connected to conflicts between the groups that aim to convert the forest into agricultural production areas and infrastructure projects and forest-dependent groups, thus resulting in what we have labeled above the "classical" deforestation frontier. Conflicts along this frontier are characterized by the high importance of social equity issues and trade-offs between environmental benefits from forests, livelihoods of different forest- 
dependent groups, and socio-economic development or growth (Brockhaus et al. 2021; Pokorny et al. 2021; Ramcilovic-Suominen et al. 2021). When the forest area reaches a context-dependent minimum, and re-afforestation begins to occur, the nature of the forest environmental frontier changes slowly, but still conflicts related to land use rights and livelihoods remain critical (De Jong et al. 2021). The increasing share of managed forests in the restored forest landscape with usually more affluent societies and higher population densities is then connected to the dominance of the conservation versus forest use frontier, which is the central pattern along forest environmental frontiers in most industrialized countries and regions in the Global North (Australia, Europe, Japan, USA), including in large countries such as Russia (Kanowski and Edwards 2021; Sotirov et al. 2021; Takahashi et al. 2021; Schultz et al. 2021; Dobrynin et al. 2021).

Finally, the evolving climate change (adaptation and mitigation) frontier characterized by both the increasing physical impacts of climate change and related disturbances and the importance of forests as subjects of climate change mitigation and adaptation policies spans across all stages of the forest transition (Schultz et al. 2021; Brockhaus et al. 2021; De Jong et al. 2021; Ramcilovic-Suominen et al. 2021; Sotirov et al. 2021). It partially reinforces other frontier conflicts, e.g., related to the polarization between conservation and forest use beliefs and interests, but may also challenge and transform existing governance arrangement and ideological constellations by the physical impacts (and related urgency to respond) of climate change on the world's forest (Schultz et al. 2021).

In other words, forest environmental frontiers and underlying conflict patterns evolve over time and space, in connection to an overall transition of forest and societies, with similar patterns occurring in similar phases of the transition at different places of the planet.

Connected to the forest transition thinking, there seems to be a pattern that forest environmental frontiers are moving toward the "dark side". The deforestation frontier destroys the primary forest with its unique biodiversity and importance for the global carbon cycle, potentially driving local forest-dependent people out of their livelihoods (Pokorny et al. 2021). Problematic patterns of equity or environmental outcomes are partially observed for subsequent policies to conserve or restore the lost forest cover (De Jong et al. 2021; Brockhaus et al. 2021; RamcilovicSuominen et al. 2021). Subsequently, fierce controversies between conservation and commercial forest use interests unfold where at least partially forest use interests seem to prevail "on the ground" (Kanowski and Edwards 2021; Dobrynin et al. 2021). Finally, climate change may be considered as an utmost frontier that will put all forests at risk.
Yet, looking more carefully, a more nuanced picture may develop of the Global Forest Environmental Frontier that is characterized by a fluctuating forest area, changing forest attributes and-often-losses of forest biodiversity (Angelstam et al. 2021), but also socio-economic gains and finally increasing societal interest in forest protection and biodiversity conservation, and, importantly, by a rich and further evolving set of policies to deal with the respective challenges (Schultz et al. 2021; Sotirov et al. 2021).

Both perspectives on the ongoing transition of the world's forests and their related societies and economics can be summarized as "Chloris" and "Hydra" worldviews (Arts 2021). The first perspective emphasizes the possibility to resolve social and environmental sustainability issues along the Global Forest Environmental Frontier and sees progress in achieving this, while the latter perceives an ongoing downward spiral of environmental destruction and social inequality related to forest destruction that could, if at all, only be reversed through a major, paradigmatic (transformational) change. Possibly, it may lie in the eye of the beholder how the evolution of the Global Forest Environmental Frontier can be evaluated in a global perspective. On one hand, deforestation connected to growing consumption of a growing world population is continuing in the tropics, and "wood mining" continues in Russia and possibly other major forest countries, despite attempts to come up with new, more sustainable forestry practices. Furthermore, climate change also creates new major challenges in forest landscapes where earlier patterns of deforestation has stopped, e.g., in the US West. Yet, at the same time, primary forest logging has halted in many (but not all) parts of the developed world and has slowed down partially in the Global South, and ambitious new environmental forest-related policies are gradually developing, for instance in the EU. Obviously, it is becoming increasingly more difficult to navigate between major transition goals such as the transition of the economy toward more renewable resources (bioeconomy), climate issues, and biodiversity conservation, next to major issues such as food and consumption for/of an ever-increasing world population.

The future will show how the Global Forest Environmental Frontier will evolve given the multiple environmental and socio-economic drivers that impact the forestpeople interface and further evolving forest policy and governance arrangements to deal with these interrelations. The papers in this special issue give manifold indications not only for this possible future evolution, but also for future research. For instance, the increasing importance of the climate change frontier-through its physical (direct) impact on forests, but also through the (indirect) impact of dynamically evolving climate policy-may shatter and reconfigure forest environmental conflicts around the 
globe, challenging familiar forest management approaches and related values, beliefs, and interests. Related to this, the necessity of a transformation of the economic system toward a system that is more relying on renewable resources and energy, and the role of forests in such a transition, puts major questions for how to govern the Global Forest Environmental Frontier, also looking into interdependencies between world regions in terms of consumption, production, and trade. To explore these patterns and interrelations, and to trace the evolution of the Global Forest Environmental Frontier in the future, will be of critical importance for both research and forest policy making. The compilation of papers in this special issue can be seen as a kind of "stock taking" for such an assessment.

Acknowledgements We express our gratitude for the financial support for this Special Issue by the Eva Mayr-Stihl Stiftung under the grant 'Fragmentierung der Internationalen Waldpolitik'. We further thank Ben Cashore, National University of Singapore, for his support to the Special Issue. We are also grateful to Lyla O'Brien for editing this paper.

\section{REFERENCES}

Angelstam, P., A.-C. Albulescu, O.D. Andrianambinina, A. Réka, E. Borovichev, W.C. Cardona, D. Dobrynin, M. Fedoriak, et al. 2021. Frontiers of protected areas versus forest exploitation: Assessing habitat network functionality in 16 case study regions globally. Ambio. https://doi.org/10.1007/s13280-021-01628-5.

Arts, B. 2021. Forest Governance: Hydra or Chloris? Elements in Earth System Governance. Cambridge: Cambridge University Press. https://doi.org/10.1017/9781108863551.

Borrass, L., D. Kleinschmit, and G. Winkel. 2017. The "German model" of integrative multifunctional forest managementAnalysing the emergence and political evolution of a forest management concept. Forest Policy and Economics 77: 16-23.

Brockhaus, M., M. Di Gregorio, H. Djoudi, M. Moeliono, T. Thuy Pham, and G.Y. Wong. 2021. The forest frontier in the Global South: Climate change policies and the promise of development and equity. Ambio. https://doi.org/10.1007/s13280-021-01602-1.

Butsic, V., M. Baumann, A. Shortland, S. Walker, and T. Kuemmerle. 2015. Conservation and conflict in the Democratic Republic of Congo: The impacts of warfare, mining, and protected areas on deforestation. Biological Conservation 191: 266-273.

De Jong, W., J. Liu, and H. Long. 2021. The forest restoration frontier. Ambio. https://doi.org/10.1007/s13280-021-01614-x.

Dobrynin, D., E. Smirennikova, and I. Mustalahti. 2020. Non-state forest governance and 'Responsibilization': The prospects for FPIC under FSC certification in Northwest Russia. Forest Policy and Economics 115: 102142.

Dobrynin, D., N.Y. Jarlebring, I. Mustalahti, M. Sotirov, E. Kulikova, and E. Lopatin. 2021. The forest environmental frontier in Russia: Between sustainable forest management discourses and 'wood mining' practice. Ambio. https://doi.org/10.1007/s13280021-01643-6

Hecht, S.B. 2012. From eco-catastrophe to zero deforestation? Interdisciplinarities, politics, environmentalisms and reduced clearing in Amazonia. Environmental Conservation 39: 4-19.
Kanowski, P., and P. Edwards. 2021. Forests under the Southern Cross: The forest environmental frontier in Australia and New Zealand. Ambio. https://doi.org/10.1007/s13280-021-01636-5.

Lane, M.B. 2003. Decentralization or privatization of environmental governance? Forest conflict and bioregional assessment in Australia. Journal of Rural Studies 19: 283-294.

Lindahl, K.B., A. Sténs, C. Sandström, J. Johansson, R. Lidskog, T. Ranius, and J.M. Roberge. 2017. The Swedish forestry model: More of everything? Forest Policy and Economics 77: 44-55.

Mather, A.S. 1992. The forest transition. Area 24: 367-379.

Pokorny, B., P. Pacheco, W. de Jong, and S. Entenmann. 2021. Forest frontiers out of control. The long-term effects of discourses, policies, and markets on conservation and development of the Brazilian Amazon. Ambio. https://doi.org/10.1007/s13280-021-01637-4.

Ramcilovic-Suominen, S., S. Carodenuto, C. McDermott, and J. Hiedanpää. 2021. Environmental justice and REDD+ safeguards in Laos: Lessons from an authoritarian political regime. Ambio. https://doi.org/10.1007/s13280-021-01618-7.

Saarikoski, H., K. Raitio, and J. Barry. 2013. Understanding 'successful' conflict resolution: Policy regime changes and new interactive arenas in the Great Bear Rainforest. Land Use Policy 32: 271-280.

Sandström, C., K. Eckerberg, and K. Raitio. 2013. Studying conflicts, proposing solutions-Towards multi-level approaches to the analyses of forest conflicts. Forest Policy and Economics 33: $123-127$.

Schultz, C., J. Abrams, E.J. Davis, A. Cheng, H. Huber-Stearns, and C. Moseley. 2021. Disturbance shapes the US forest governance frontier: A review and conceptual framework for understanding governance change. Ambio. https://doi.org/10.1007/s13280-02101629-4.

Seijger, C., D. Kleinschmit, D. Schmidt-Vogt, M. Mehmood-UlHassan, and C. Martius. 2021. Water and sectoral policies in agriculture-forest frontiers: An expanded interdisciplinary research approach. Ambio. https://doi.org/10.1007/s13280-02101555-5.

Sotirov, M., and G. Winkel. 2016. Toward a cognitive theory of shifting coalitions and policy change: Linking the advocacy coalition framework and cultural theory. Policy Sciences 49: $125-154$.

Sotirov, M., and S. Storch. 2018. Resilience through policy integration in Europe? Domestic forest policy changes as response to absorb pressure to integrate biodiversity conservation, bioenergy use and climate protection in France, Germany, the Netherlands and Sweden. Land Use Policy 79: 977-989.

Sotirov, M., G. Winkel, and K. Eckerberg. 2021. The coalitional politics of the European Union's environmental forest policy biodiversity conservation, timber legality, and climate protection. Ambio. https://doi.org/10.1007/s13280-021-01644-5.

Takahashi, T., W. de Jong, H. Kakizawa, M. Kawase, K. Matsushita, N. Sato, and A. Takayanagi. 2021. New frontiers in Japanese forest policy: Addressing ecosystem disservices in the 21st Century. Ambio. https://doi.org/10.1007/s13280-021-01566-2.

Winkel, G. 2014. When the pendulum doesn't find its center: Environmental narratives, strategies, and forest policy change in the US Pacific Northwest. Global Environmental Change 27: 84-95.

Yasmi, Y., J. Guernier, and C.J.P. Colfer. 2009. Positive and negative aspects of forestry conflict: Lessons from a decentralized forest management in Indonesia. International Forestry Review 11: 98-110. 
Publisher's Note Springer Nature remains neutral with regard to jurisdictional claims in published maps and institutional affiliations.

\section{AUTHOR BIOGRAPHIES}

Georg Winkel $(\varangle)$ is Head of the Governance programme and Bonn Office of the European Forest Institute; he is also an associate professor at the Universities of Freiburg and Bonn. His research focusses on forest and environmental policy and sociological questions related to land use and conservation.

Address: European Forest Institute, Governance Programme, Platz der Vereinten Nationen 7, 53113 Bonn, Germany.

e-mail: georg.winkel@efi.int

Metodi Sotirov is Senior Researcher and Associate/Assistant Professor in Forest and Environmental Policy at the University of Freiburg. His research interests include the analysis of policy change and coalitional politics across global, EU, and national levels of governance in the domains of forestry and land use, nature protection and biodiversity conservation, climate protection, and commodity trade. Address: Faculty of Environment and Natural Resources, Institute of Environmental Social Sciences, Chair of Forest and Environmental Policy, University of Freiburg, Tennenbacher Str. 4, 79106 Freiburg, Germany.

e-mail: metodi.sotirov@ifp.uni-freiburg.de

Cassandra Moseley is Vice President for Research, University of Oregon and Director of the Ecosystem Workforce Program. Her expertise is in political theory and collaborative governance, with decades of research experience in the US Pacific Northwest and in Latin America.

Address: University of Oregon, Eugene, OR 97403-5247, USA.

e-mail: cmoseley@uoregon.edu 